\title{
Notícias de uma guerra particular: \\ Percursos de projeto de extensão emaranhando estudos de gênero e discursos curriculares
}

Jorge Marçal

Paula Lemos ${ }^{2}$

Thiago Ranniery ${ }^{3}$

\begin{abstract}
Resumo: A partir das oficinas de formação de professores da rede pública na cidade do Rio de Janeiro, esse ensaio explora os emaranhamentos entre estudos de gênero e discursos curriculares. Tendo por foco aflições e anseios relatados por professores, nós apontamos tanto para os limites morais através dos quais o gênero é incorporado pelo discurso pedagógico quanto para os processos de generificação de práticas curriculares. Nesses percursos, interrogamos sobre que pode significar a ação política de um projeto de oficinas, cuja força está em abrir um espaço-tempo de suspensão, no qual gênero deixa de ser objeto de ensino e se torna um modo de olhar e de eletrizar categorias, de estranhar o próprio mundo, de encontrar a diferença.
\end{abstract}

Palavras-chave: Gênero. Currículo. Oficinas de Formação. Professores.

\section{News from a particular war: \\ Pathways of an extension project on gender studies and curriculum discourses}

\begin{abstract}
From the teacher training workshops at public schools in the city of Rio de Janeiro, this essay explores the entanglements between gender studies and curricular discourses. From the afflictions and longings reported by teachers, we point both to the moral limits through which gender is incorporated by the pedagogical discourse and to the processes of generalization of curricular practices. In these journeys, we questioned what the meaning is of the political action of a workshop project, whose strength lies in opening a space-time of suspension, in which gender ceases to be the object of teaching and becomes a way of looking and electrifying categories, to wonder at the world itself, to find the difference.
\end{abstract}

Keywords: Gender. Curriculum. Training workshops. Teachers.

\footnotetext{
${ }^{1}$ Licenciando em Ciências Biológicas - UFRJ - Bolsista de Iniciação Científica da FAPERJ no Laboratório Núcleo de Estudos Curriculares (LaNEC/FE/UFRJ).E-mail: jorgefelipemgomes@gmail.com

${ }^{2}$ Mestranda em Educação do Programa de Pós-Graduação em Educação em Educação e Membro do Laboratório Núcleo de Estudos Curriculares (LaNEC/FE/UFRJ).E-mail: paulacdelemos.bio@gmail.com

${ }^{3}$ Professor do Programa de Pós-Graduação em Educação em Educação da Faculdade de Educação da Universidade Federal do Rio de Janeiro e Pesquisador do Laboratório Núcleo de Estudos Curriculares (LaNEC). E-mail: t.ranniery@gmail.com
} 


\section{Eletrizar categorias}

Nossa tarefa é criar problemas, provocar uma resposta potente a eventos devastadores, bem como assentar águas turbulentas e reconstruir lugares calmos (HARAWAY, 2016, p. 1).

Oito de março de 2018. São duas da tarde, de um dia quente no Rio de Janeiro. Dois estudantes de licenciatura e um professor universitário se dirigem a uma escola pública na Ilha do Govenador, Rio de Janeiro. Nós respondíamos a um convite para oferecer uma oficina aos estudantes de oitavo e nono ano do segundo ciclo do fundamental sobre o Dia Internacional da Mulher. O tema que nos pediram: violência de gênero. Dias antes, a professora que intermediou o convite expressou sua preocupação com as relações entre os meninos e meninas no intervalo das aulas, pautada por assédio e violência. Talvez, por não ser nossa primeira experiência com jovens da periferia das favelas cariocas, ou quem sabe por uma inquietação de nossa parte, seguimos com alguma desconfiança para as duas sessões de conversa que promovemos naquela tarde. A primeira delas apenas com as meninas; a segunda com os meninos. A metodologia era inspirada no Teatro Imagem, uma das muitas possibilidades do Teatro do Oprimido. No debate que se seguiu: ouvimos sobre violência e gênero, mas em categorias e formas cujas conexões desafiam os enquadramentos com o qual o pensamento curricular vem incorporando a ação teóricopolítica em torno de gênero, sexualidade e estudos feministas. Há certo descompasso, como que uma nota desafinada, de um pensamento cuja forma normativa pode funcionar como uma simplificação tão violenta quanto aquilo que critica sobre o mundo e a vida.

Começamos explicitando tal preocupação porque no acirramento da disputa política em torno da educação - e sabemos que "acirramento" é um eufemismo - currículo tomou, em diagnóstico que não é tão recente, centralidade. No entanto, na topologia das políticas curriculares recentes, como exposto por Macedo (2017a), mesmo posições que nos parecem tão divergentes em relação à escola - levantes por uma escola sem partido, por uma escola preocupada com a justiça social ou por uma escola pautada pelas avaliações - parecem intimamente ligadas e intercambiáveis pelo que autora chama de normatividade neoliberal. O argumento da autora se inspira naquilo que Brown (2015) nomeou de economização da vida que "toma forma como uma racionalidade de governo, estendendo uma formulação específica de valores, práticas e métricas para todas as dimensões da vida humana” (BROWN, 2015, p. 30). Segundo Macedo (2017b), o fomento de políticas de reconhecimento de "cidadãos" ou de grupos minoritários embebido na gramática política da normatividade, abduz o risco de que o currículo acabe se tornando “também (e até primordialmente) parte da própria prática de ordenar e regular os sujeitos de acordo com as normas pré-estabelecidas” (MACEDO, 2017b, p. 547). Nós começamos, assim, a nos interrogar sobre o tipo de trabalho que um projeto de extensão com gênero e sexualidade pode empreender pelo tipo de imaginação que as tentativas de "resolver os problemas" nos colocavam. 
Provocados, fomos nos descolando para aquilo que Haraway (2016, p. 1) chamou, em uma tradução um tanto livre, de viver com o problema, o que "requer aprender a estar verdadeiramente presente, não como um pivô que desaparece entre o passado horrível ou idílico e os futuros apocalípticos ou salvadores, mas como criaturas mortais entrelaçadas em uma miríade de configurações inacabadas de lugares, tempos, assuntos e significados". Esse ensaio é, pois, fruto parcial de um conjunto de oficinas, parte de um projeto extensão, que estamos realizando desde 2016 com estudantes e professores em escolas públicas do Rio de Janeiro sobre gênero e política. Talvez, esse texto deva mesmo ser lido como as primeiras notas, ainda tateantes, por certo, que buscam expor intuições embrionárias, se não suficientemente amadurecidas, ao menos autônomas o bastante para problematizar como categorias do discurso curricular erguem armadilhas morais - ou mais, propriamente, moralizantes - que podem curtocircuitar qualquer resposta ético-política à diferença. Em retrospecto, a massa de transcrições e relatos das oficinas foi se revelando menos empolgante do que parecia à primeira vista, permitindo-nos dar conta de que, em meio ao crescente interesse pelas temáticas de gênero e sexualidade nas escolas, era preciso recolar uma interrogação interessada antes que uma exclamação ou mesmo um ponto final. Sabemos que a expressão "crescente interesse" pode soar estapafúrdia dentro da paisagem política no qual o projeto vem sendo desenvolvido, mas, nossa intuição, seguindo uma indicação de Paraíso (2016a), tem captado antes uma proliferação ramificada, espraiada, do debate nas escolas, entre professores. No entanto, quanto mais percorríamos as escolas, mais a nossa sensação era de uma espécie de esgotamento ou mesmo sufocamento, não tanto pelo que imaginávamos, mas de que somos levados ao nos debater, fantasmagoricamente presos, diante do nosso próprio rosto.

É como se não houvesse modos alternativos de conceituar a ação política das escolas e professores: as únicas opções parecem ser ou a ingenuidade do voluntarismo ou as histórias unilaterais da transformação total e da redenção. De algum modo, o que vamos sugerir se desdobra a partir de um uso deslocado de Barad (2003) de que ação política é um emaranhamento, um "contínuo reconfigurar do mundo" (BARAD, 2003, p. 818); não um atributo ou propriedade de um sujeito, mas um fazer/ser performativo em atividade. Daí porque a referência no título ao documentário Notícias de uma guerra particular não é, de todo, despropositado. Trata-se de uma citação performativa que, longe da pretensão realista do filme de João Moreira Sales e Katia Lund de 1999, recoloca um jogo conceitual com o discurso curricular que permanecerá como pano de fundo deste texto. A tomada das questões que, aqui, traremos, ou das formas morais que nos percorrem e correm entre nós, professores, é "uma luta contra amnésia com o objetivo de encontrar aquelas formas de coexistência reveladas pelas histórias convergentes e ressoantes" (BUTLER, 2017, p. 117). Como corolário, argumentamos que tal tomada conforma mesmo uma guerra; não uma guerra contra o outro, quem quer que seja, mas uma guerra com o nosso próprio mundo - para parafrasear Latour (2002) - para que a alteridade possa passar. Ou seja, esse ensaio não é nada mais que notícias de um projeto de extensão que, se em seu começo, buscou eletrizar as categorias de gênero e sexualidade com as quais professores e estudantes operavam - a pretensão iluminista da 
revelação - se viu obrigado a tornar problemáticas as próprias categorias com as quais o discurso curricular opera; aquelas que nos levam a imaginar um lugar seguro, o que, por vezes, implica impedir que algo venha a acontecer.

Nesses percursos, entrelaçamos três indagações. Primeiro: aquela que busca suspender os limites da equivalência entre currículo e conteúdo a ser ensinado. Segundo: aquela que insiste que o currículo é parte da constituição normativa das categorias generificadas e sexualizadas pelas quais formas de vida são constituídas; terceira, como consequência das duas afirmações anteriores, aquela que envolve a reativar uma política de imaginação que não precise extirpar a diferença subsumindo-a ao que já parece dado, ao que já se conhece e, especialmente, ao que se pode ensinar (RANNIERY, 2017a; 2017b). Vamos focar, na próxima sessão, em elementos das oficinas endereçadas aos professores. Oficinas que foram montadas a partir das demandas que cada escola foi nos apresentando, a cada convite que fomos recebendo para debater gênero e sexualidade. Nelas, tais demandas não eram mobilizadas em torno de uma solução ou de um projeto definido com a pretensão de esgotar gênero e sexualidade a temas ensináveis (RANNIERY; LEMOS, 2018), mas para pensarmos que frentes de possibilidades poderiam se abrir, que tensões poderiam ser produtivas na relação com os diferentes agentes ali presentes. Nós gostaríamos, assim, de insistir que não estávamos preocupados em levar conhecimentos sobre o que é gênero ou o que é sexualidade para os professores, ensinando como esse corpo epistemológico poderia ser aplicado à sala de aula, como reconhecer possíveis vítimas ou de que forma é possível construir uma escola diversa e socialmente emancipada. Por outra via, concordando que "o caráter produtivo do poder faz com que pipoquem potencialidades subversivas aqui e ali quando qualquer norma é posta em funcionamento" (MACEDO, 2017, p, 517a), buscamos tecer conexões a partir de gênero como categoria teórica, como fator complicador e não como pressuposto para qualquer debate.

Nossa proposição é de que as oficinas estão mais para espaços-tempos de composição. São encontros nos quais a expectativa não é sobre uma formação ou preparação do professor para um futuro que virá, para uma sexualidade (saudável), para uma convivência harmoniosa entre as diferenças, entre outras opções disponíveis. Não se trata, por sua vez, de exaltar o cotidiano escolar, como se este estivesse apartado de relações de poder, tampouco assumir uma posição de neutralidade - como se tal crença ainda fosse possível -, mas de ativamente e afetivamente assumir o que as articulações entre diferentes agentes nas escolas podem nos trazer, apostar no encontro. O que aprendemos nesse projeto é que tal encontro é possível sob as condições nas quais estamos dispostos a arriscar a própria pele, a eletrizar as categorias do pensamento curricular com as quais imaginamos o mundo, "uma resposta energizante a um campo altamente carregado” (BARAD, 2015, p. 397). Isto é, quando nossas categorias são lançadas em um campo provocado pela ação de forças, quando são, para escrever com Barad (2015), dispersas e difratadas através do tempo e do espaço. 


\section{Aflições sobre gays, meninos-violentos e meninas-vítimas}

Nosso ponto de escora para a montagem das oficinas são as inquietações dos professores sobre o que eles pensam e identificam a respeito das questões de gênero e sexualidade e como isso tem marcado a vida da escola que lecionam. Nossas preocupações iniciais em torno desse ponto de partida eram tentar entender as categorias através das quais leem, discutem, questionem, assistem em novelas, veem nos filmes, escutam de movimentos sociais. O primeiro movimento que destacamos é aquele no qual gênero passa a recobrir, quase que exclusivamente, a inclusão de estudantes gays e travestis nas escolas. O que aflige, a principio, é como a transposição de gênero para escola torna-se sinônimo de como aprender direcionar olhares para estudantes com gays e travestis, é sobre aprender a nomeá-los e tratá-los de forma correta. É como se a operação classificatória de experiências de gênero de sexualidade tomadas por não lineares, seu encaixe em alguma categoria disponível trouxesse o alívio. Em ocasiões diferentes, Ranniery (2017b; 2017c) sinalizou que a sintomática conversão de gênero e sexualidade em abordagens inclusiva de sujeitos diferentes toma ambos como recursos descritivos que apenas revelariam evidências corporais e subjetivas suspostamente inerentes. Apesar de esse deslocamento merecer alguma interrogação, não desejemos perder de vista que tal conexão é também um modo de relação e engajamento. Logo, fomos impelidos a desafiar os professores que nos convidam: o que acontece se pensarmos por outro ângulo? Se estabelecermos outro ponto de partida? E se começássemos da avaliação, do planejamento, da organização das práticas pedagógicas como generificadas, por exemplo?

Ao considerar que a escola é "um importante espaço social, em que as normas reguladoras do gênero marcam sua presença para ensinar o certo, o errado, o esperado, o adequado, o inadequado, o normal, o anormal, o estranho e o "abjeto" em relação às condutas de gênero" (PARAÍSO, 2016b, p. 208), nós convidamos professores a elencar as características do que estabelecem como um bom e um mau aluno. A resposta inicial ao desafio vem, quase sempre, acompanhada de algum desconforto, mas as considerações cedem rapidamente espaço para alguns elementos que se repetem. Espera-se que um "bom aluno" seja, por exemplo, aquele que tenha os seguintes atributos: participação ativa em sala de aula, engajamento com as atividades propostas, bom comportamento, respeito à autoridade docente e organização. Tais atribuições são tomadas como femininas, de modo que há um conflito de gênero entre o tornar-se aluno e tornar-se menino (REIS; PARAÍSO, 2014). A afirmação costuma constranger os professores para, em seguida, suas histórias indicaram que aqueles meninos que desempenham atitudes de bons alunos são ou foram comumente imaginados, ao menos em algum momento, como "gays". Afinal como Butler (2003) notou aparência de gênero como substância, como uma classe de ser, é performativamente instalado pela reiteração de uma série de gestos, movimentos e estilos corporais que criam a ideia de um corpo como gênero constante.

É, nesse sentido, que aquilo que Cechetto (2004) descreveu como estilos de masculinidades 
produzem especificidades entrelaçadas ao discurso pedagógico na constituição generificada de meninosalunos - uma categoria na qual desleixo e violência, desafio à autoridade e desorganização se encontram. Este é um dos muitos exemplos através do qual as oficinas emaranham estudos de gênero e discursos curriculares a fim de responder ao convite de Paraíso (2016a, p. 209), no qual "é necessário desaprender e "desfazer-nos" de todo um sistema de raciocínio generificado que tem sido acionado nos currículos e que diferenciam, hierarquizam e excluem na escola" para com isso "abrir os corpos" (PARAÍSO, 2016a, p. 209) para encontrar a diferença. A crítica à generificação das práticas curriculares funciona para conferir inteligibilidade às suposições habilitadoras de uma série de binários que tornam possível conceber a vida na escola. Além disso, é uma crítica que trabalha para descrever as transformações generificadas e os efeitos dessas transformações em situações locais, específicas e históricas. É um esforço de fazer gênero funcionar como uma lente difrativa do currículo, isto é, que reativa aquilo que escapa, aquilo que estremece e desloca, os atravessamentos, as relações. Difração, nota Barad (2014, p. 183), é um modo de figurar a diferença em "uma multiplicidade, uma superposição/emaranhamento de partes (aparentemente) díspares". Com efeito, temos insistido que gênero não designa um objeto a ser ensinado e que tal abdução no reconhecer tipos de sujeitos previamente instituídos, obscurece as alianças imprevisíveis e difíceis que as formas generificadas da linguagem da pedagogia buscam obliterar.

Nossa insistência de que de há um jogo de gramáticas de gênero imanente à imaginação pedagógica, na qual “o ensino das palavras se vincula sutilmente às relações de poder e à tecnologia de gênero" (CALDEIRA; PARAÍSO, 2016, p.762), é, por assim dizer, que tais reiterações podem "limitar possibilidades para algumas e aumentar possibilidades para outros" (CALDERIA; PARAÍSO, 2016, p.761). De fato, Paraíso (2016) exemplifica como funciona esse processo de generificação das práticas curriculares, que marca desde profissões, até cores e comportamentos. Entretanto, de certa maneira, temos sido compelidos suspeitar das aflições, que embora não possam ser desprezadas, tomam gênero como enfrentamento das desigualdades e da discriminação entre homens e mulheres, em especial de defesa do papel da escola nas políticas (não entendo apenas como as advindas do Estado) de enfrentamento a violência através da quais determinadas vidas são empurradas para a morte. Longe de alguma linearidade ou maniqueísmo, o que temos acompanhado é um deslocamento semântico por meio do qual a promoção do debate de gênero traduz anseios pela produção de um outro estável na figura da vítima.

Ao traçar a emergência da figura da vítima, Sarti (2011) argumenta que sua materialidade está embutida na disputa para legitimar moralmente as demandas sociais de reparação e cuidado e conferirlhes inteligibilidade. Outra parte das oficinas veio exatamente de convites de professores preocupados com a violência sobre as meninas nos intervalos escolares praticados pelos colegas. Por mais bem intencionados que tem sido os propósitos e na inegável importância política de tentar resolver a invisibilidade de tensões e conflitos dessa natureza, é preciso indagar sobre os limites da gramática curricular em sua incorporação. Quase sempre, há uma vontade ou intencionalidade de formar meninos 
capazes de reconhecer o lugar de vulnerabilidade das meninas, o que justificaria sua proteção contra as violências. A partir disso, dois atores emergem para construir essa relação. As meninas como vítimas e os meninos como violentos; esses, por sua vez, para evitarem tal configuração, precisariam ser educados para protegê-las. Ao discorrer sobre a literatura especializada sobre violência e gênero no Brasil na década de 1980, Gregori (1993) observa que nos estudos predominava uma tendência a alimentar ou mesmo mimetizar a trama assimétrica que constituía as relações perpassadas pela violência. Sua crítica foi elaborada no sentido de alertar para o efeito "vitimizador" de uma série de convenções explicativas e descritivas presentes no tratamento político e acadêmico da violência contra a mulher. O que procuramos realçar é que essas avaliações, aparentemente contraditórias, - inclusão de estudantes gays e proteção às meninas - demonstram que as aflições estão mais vinculadas com questões de ordem moral, cuja função adequada da escola seria atar os indivíduos "às normas e aos valores compartilhados, como honra, vergonha, obrigação, confiança, fidelidade e compromisso com os outros” (DEBERT, GREGORI; 2008, p. 174-175).

A construção vítima não está blindada de relações de poder contingenciadas e contextuais, de modo que sua imagem não está de fora da relação. Dito de outro modo, o discurso pedagógico se vê diante seu próprio limite moral ao incorrer em uma visão que enfatiza a relação "meninos-violentos" e “meninas-vítimas" a partir de convenções que reiteram, em vez de questionar, a dualidade vítima e algoz e faz escorrer as relações de violência para os termos do voluntarismo ou ainda da dicotomia tradicional versus moderno. Nesse marco, as meninas são colocadas "em posição de quem precisa ser cuidada e não em posição de igualdade" (CALDEIRA; PARAÍSO, 2016, p. 770). Se, antes a subordinação das mulheres seria através da violência, agora esse lugar subalterno desliza para o protecionismo, que funciona como ponto de escora através do quais meninos são responsáveis para algum tipo de avanço progressista de si e do mundo ao protegerem as meninas. Certo imaginário que a escola faz e deve fazer, do que e quem são professores e qual o seu papel, termina por bloquear outras possibilidades de "desconstruir os discursos contemporâneos sobre a violência - e o lugar atribuído à vítima nesses discursos -, buscando compreender a lógica na qual se inscrevem e empreender uma análise distanciada que permita abrir o caminho para uma política e uma intervenção social efetivas em seu enfrentamento” (SARTI, 2011 p. $58)$.

Um dos marcos que busca suturar esse caminho político é a conversão da escola, por pressuposto, em uma instituição responsável por apaziguar os conflitos sociais, emancipar os sujeitos de estruturas que os violentam, em especial a partir da transformação de gênero em conteúdo. Tal demanda, ainda que pareça servir de instrumento de ação política, perde força analítica e, portanto, política porque supõe coerência e obviedade dos termos educacionais, inexistente na dinâmica que constitui as relações, e supõe ser possível tornar previsível o incontrolável da vida escolar. Não se trata, entretanto, de culpar a escola e professores pelo que quer que seja. Nosso desejo é entender como o discurso pedagógico moraliza o debate de gênero e sexualidade na escola com categorias, elas também, marcadamente generificadas e 
sexualizadas, pois atua "produzindo formas de experiência de si nas quais os indivíduos podem se tornar sujeitos de um modo particular" (LARROSA, 1994, p. 57). Dessa forma, as aflições por respostas políticas, ancoradas nas fantasias morais de proteção e inclusão, dependem de "de uma certa imagem das pessoas e das relações entre as pessoas: que cada um tem determinadas qualidades pessoais, que é possível conhecê-las e avaliá-las segundo certos critérios, que é possível mudar coisas em si mesmo para ser melhor e conseguir o que a pessoa se propõe, que as outras pessoas têm qualidades diferentes, [...] que é possível viver juntos, apesar das diferenças, dadas certas atitudes de compreensão, respeito e tolerância, etc. (LARROSA, 1994, p 58). Em resumo, dos meninos-violentos aos meninos-zeladores, das meninasvítimas aos meninas-protegidas, do reconhecimento dos estudantes diferentes, os gays, à construção da sensibilidade política à violência, este tipo de ancoragem imaginativa retoma e recoloca o sujeito humanista autodeterminado, capaz, por si só, de alterar seu próprio destino.

Dessa consideração deriva uma constatação que, inegavelmente, traz dificuldades para a ação política, incluindo para um projeto de extensão que emaranha estudos feministas e pensamento curricular e, em especial, para aquelas fantasias desejosas de explicações e soluções, sedentas por inimigos essenciais e que sempre nos permeiam. Primeiro, porque, como apontou Larrosa (1994), o espaço pedagógico já não pode ser visto como "um espaço neutro ou não-problemático de desenvolvimento ou de mediação, como um mero espaço de possibilidades para o desenvolvimento ou a melhoria do autoconhecimento, da auto-estima, da autonomia, da autoconfiança, do autocontrole, da auto-regulação, etc., mas como produzindo formas de experiência de si nas quais os indivíduos podem se tornar sujeitos de um modo particular.” (LARROSA, 1994, p. 57). Segundo, como corolário, os sujeitos são, pois, "redutos incessantes de recodificação de identidades seguras" (SPIVAK, 1993, p. 211) que se sobrepõem e sedimentam e que são, por efeito, palimpsestos. A ação política que pensamos ser possível parece está na decodificação e recodificação dessas categorias que nos (com)formam dentro de formações discursivas e práticas culturais. Inspirados em Butler (1995), nós começamos a duvidar que a ação política da escola e professores seja possível a partir de uma base transcendental sobre o que é a educação, o currículo, ou que quer que seja. Estar tão enraizado nela é quase ser enterrado, é recusar a alteridade, rejeitar a contestação, diminuir o risco de transformação perpetuamente colocado.

O emaranhamento que estamos defendendo insiste que a força política de gênero nos discursos curriculares “está aberto a formações que não estão totalmente restritas antecipadamente" (BUTLER, 1995, p. 135). As respostas, portanto, sobre que ação política é possível quando gênero e currículo são entrelaçados parecem, por sua vez, emergir não dentro de uma função essencial da escola, mas nas relações que a constituem entre uma multiplicidade de forças, linguísticas e materiais, enquanto lutamos com (e não contra) o desejo, a política e a multiplicidade de códigos produzidos pela regulação do discurso e da prática. Se esse ensaio é sobre as oficinas, não é, certamente, sobre como respondemos ou buscamos encontrar respostas para viver com essas relações. Tentar localizar e nomear respostas é mais uma variação da busca por controle. De qualquer forma, viver com as relações depende de reconhecer que o 
significado do que pode ser inventado é incognoscível; depende de uma habilidade de usufruir da ambivalência assim como da crítica das categorias que limitam nossa imaginação. Se as oficinas foram sobre algo, foram sobre levar quem nos convidava e nos levar a estranhar o próprio mundo. Seguindo Stengers (2018, p. 446), "trata-se justamente de desacelerar a construção desse mundo comum, de criar um espaço de hesitação a respeito daquilo que fazemos". Enfim, as aflições sobre currículo e gênero não podem ser esgotadas ou estagnadas na simples permissão "ao sujeito se reconhecer na cultura" (MACEDO, 2017b, p. 540), um passaporte para autorizar o outro viver desde que caiba "numa lógica do re-conhecimento comprometida com a crença humanista e suas pretensões emancipatórias" (MACEDO, 2017b, p.541). Gênero, quando deixa de ser um objeto de ensino, um conteúdo compartimentalizado, nos permite que este conceito teórico eletrize categorias, que as atravesse, que crie potência, e concede formas de existência.

\title{
Eu canto o corpo elétrico: um emaranhamento indeterminável
}

\author{
O que é a mulher? Pânico, alarme geral para uma defesa ativa. Francamente, este é \\ um problema que as lésbicas não têm por causa de uma mudança de perspectiva, \\ e seria incorreto dizer que as lésbicas se associam, fazem amor, vivem com \\ mulheres, pois "mulher" tem significado apenas em sistemas de pensamento \\ heterossexuais e em sistemas econômicos heterossexuais. As lésbicas não são \\ mulheres (WITTIG, 1980, s/p).
}

A citação de Wittig (1980) mobiliza bem mais do que uma crítica a afirmações universais sobre uma natureza supostamente estática. Em uma cartografia do feminismo no campo educacional, St. Pierre (2010), embora assuma, não sem razão, o caráter contestado do termo “feminismo", escreve sobre a dificuldade e a complexidade do trabalho a ser realizado, precisamente porque envolve um afastamento contínuo das subversões autorizadas que proliferam categorias unificadas, petrificadas, universais. Como Braidotti (2000), certa vez, afirmou as teorias feministas não são apenas sobre a denúncia do universalismo, também são sobre a invenção de outros modos existência, "espaços nos quais é possível se engendrar novas formas alternativas de ação" (BRAIDOTTI, 2000, p. 35). O que estamos chamando, mesmo que de forma canhestra e com alguma desconfiança, de emaranhar estudos de gênero e discurso curriculares é sobre trazer à tona categorias do discurso pedagógico deslocadas de seu usual. Este trabalho de deslocarem-se, nos pareceu, cada vez mais crucial, à medida que erámos interpelados a responder as demandas, quase sempre traduzidas em angústias e aflições, de professores e escolas e, no mesmo passo, estranhar os tipos de pressuposições que tais interpelações e quaisquer que fossem nossas respostas a elas eram obrigadas a estabelecer. Para nós, hoje, esse é o desafio do entrelaçamento mais vigoroso dos estudos feministas em educação: abrir formas de composição política que envolve a tarefa persistente de “criticar uma estrutura que não pode (não desejar) habitar” (SPIVAK, 1993, p. 284).

Spivak (1993, p. 130) lembra que "qualquer ato deve assumir termos unificados para começar"; 
logo, inevitavelmente, em nossa urgência, somos levados a cometer desentendimentos de fundamentação quando tentamos aterrar e ação política em categorias tão complexas quanto as que sustentam o discurso curricular. Se pudéssemos encerrar esse ensaio com alguma liberdade de sugerir algo, esta sugestão poderia ser resumida no fato de que o emaranhamento entre estudos de gêneros e educação materializam uma agenda política própria, aquela de deslocar a imaginação do pensamento curricular que, como qualquer narrativa política, deve ser interrogada por suas condições habilitadoras. A postura da crítica persistente "do que não se pode não querer" (SPIVAK, 1993, p. 46) implica um trabalho constante e aberto o suficiente de emaranhamento porque envolve bagunça, suspensão e lançamento de nossos conceitos mais seguros ao mundo; um trabalho que está ainda por ser feito e que, muito provavelmente, não terminará nem pode ser previsto de antemão. Inspirado em Spivak (1993), é possível ainda sugerir que esse entrelaçamento é, antes de qualquer coisa, uma prática de "questionar a autoridade do sujeito investigador sem paralisá-lo, transformando persistentemente as condições da impossibilidade em possibilidade" (SPIVAK, 1993, p. 201). É um exercício de manter acesas as faíscas de que "o que eu não consigo imaginar mantém a sentinela sobre tudo aquilo que eu devo fazer, pensar, viver" (SPIVAK, 1993, p. 22). Este trabalho nos limites da inteligibilidade é excitante e cativante de muitas maneiras. E, claro, nos lembra, que quando gênero e sexualidade assumem formas notáveis na arena da política curricular devemos estar dispostos a nos mover "para além deles, na medida em que se tornam constrangedores, incapacitantes ou comprometedores" (SPIVAK, 1993, p. 7).

Não há dúvida que esse movimento pode ser doloroso e até incômodo, mas também pode ser prazeroso e desejante, o que Lather (1996, p. 3) descreveu como "fazendo e incomodando simultaneamente". Isto posto, resta interromper a narrativa progressista da redenção educacional e seus juízos morais, ou ainda avaliar o que ela produz e contínua a produzir na forma de tantas categorias inescrutáveis na arena política. Por fim, a heterossexualidade, ou a matriz heteronormativa, nos conhecidos termos de Butler (2003), não aparece apenas como uma das possibilidades numa miríade de orientações sexuais, mas como um sistema de pensamento que torna impensável tudo que não é possível dentro de suas categorias de imaginação. Se, na conclusão de Macedo (2017b, p. 547) "este ser cidadão se converte, como nos discursos curriculares, em um projeto de reconhecimento sustentado pela norma [...] não há espaço para a tematização dos termos em que o reconhecimento se dá”, não é despropositado indicar que, se gênero se converte, nos discursos curriculares, em um projeto de ensino capitaneado pela funcionalização de uma identidade, o espaço para a tematização dos próprios termos em que o discurso pedagógico se dá não é apenas constrangido, mas refuncionaliza a (hetero)normatividade. Esta discussão de como determinados conceitos, uma vez garantidos pelo discurso curricular e pedagógico, tornaramse inteligíveis de forma generificada e sexualizada sugere a força sedutora desse trabalho de entrelaçamento. Esse espaço-tempo de conexão não é mesmo sobre oferecer respostas certas ao que professores devem fazer, mas sobre a responsabilidade com as relacionalidades animadas daquilo que Haraway (2008) chamou de tornar-se com, essas emaranhadas materializações que ajudamos a conectar, 
incluindo novas configurações, novas subjetividades, novas possibilidades

Agarrar essa chance de "esburacar o controle, deixando emergir os sentidos que ele quer excluir" (MACEDO, 2017a, p. 520) envolve, enfim, devolver a possibilidade de ecoar e amplificar esses sentidos excluídos em nosso próprio trabalho, em nosso próprio, um eco que "mudaria nossa própria sensação de tempo [...] e nesse momento poderia haver a chance para algo diferente” (BUTLER, 2017, p. 117). Alguém poderia desconfiar do tipo de trabalho que estamos sugerindo, mas trata-se de uma desconfiança que ignora o desconfortável que as categorias fazem em muitos de nós. Alguém poderia ainda tratá-lo como menor, ou mesmo desnecessário e, quiçá, um tanto idiota ante a urgência de nosso tempo. Stengers (2018) sugere, entretanto, que o idiota "é aquele que sempre desacelera os outros, aquele que resiste à maneira como a situação é apresentada, cujas urgências mobilizam o pensamento ou a ação". Trata-se de desacelerar o pensamento, de pensar em presença daqueles interessados no que estamos articulando sem que mimetizemos uma bola de demolição ontológica do outro (RANNIERY, 2018). Isto é, de arriscar os termos em que nos articulamos, mantendo o desconhecido divergente, “contra a tentação de uma paz que se pretenderia final, ecumênica, no sentido de que uma transcendência teria o poder de requerer daquele que é divergente que se reconheça como uma expressão apenas particular do que constitui o ponto de convergência de todos" (STENGERS, 2018). Esse espaço-tempo de esgarçamento tenciona não apenas o deslizamento de gênero e sexualidade para a qualidade de objetos de ensino a serem introjetados nas escolas via formação de professores, mas limites morais através dos quais essa transformação ocorre. Poderíamos falar antes, com um risco que gostamos de flertar, de deformação - esse é um nome instigante para esse trabalho nas fissuras e atritos, esse trabalho de indeterminação e inconstância, ali onde gênero e sexualidade são forças constitutivas dos currículos, de onde nunca estiveram fora; ali onde revelam o terreno infinitamente rico de imaginar possibilidades de viver e morrer de outra forma; ali onde o poeta Walt Whitman (2011) insistiria eu canto o corpo elétrico.

\section{REFERÊNCIAS}

BARAD, Karen. Posthumanist Performativity: Toward an Understanding of How Matter Comes to Matter. Signs: Journal of Women in Culture and Society, v. 28, n. 3, 2003.

BARAD, Karen. TransMaterialities: Trans*/Matter/Realities and Queer Political Imaginings. GLQ: A Journal of Lesbian and Gay Studies, v. 21, n. 2-3, p. 387-422, 2015.

BARAD, Karen. Diffracting Diffraction: Cutting Together-Apart. Parallax, v. 20, n.3, p. 168-187, 2014.

BRAIDOTTI, Rosi. Sujetos nómades: corporización y diferencia sexual em la teoria feminista contemporánea. Buenos Aires: Paidós, 2000.

BROWN, Wendy. Undoing the demos: Neoliberalism's stealth revolution. New York: Zone Books, 
2015.

BUTLER, Judith. Caminhos divergentes: judaicidade e crítica do sionismo. São Paulo: Boitempo Editorial, 2017.

2003

. Problemas de gênero: feminismo e subversão da identidade. São Paulo: Civilização Brasileira,

. For a careful reading. In: Benhabib; BUTLER, Judith; CORNELL, Drucilla; FRASER, Nancy. Feminist contentions: a philosophical Exchange. New York: Routledge, 1995. 127-143.

CALDEIRA, Maria Carolina da Silva; PARAÍSO, Marlucy Alves. Tecnologias de gênero, dispositivo de infantilidade, antecipação da alfabetização: conflitos na produção de corpos generificados. Educação \& Pesquisa, São Paulo, v. 42, n. 3, p. 755-772, jul./set. 2016.

CECCHETTO, Fátima. Violência e estilos de masculinidade. Rio de Janeiro: Editora FGV, Rio de Janeiro, 2004.

DEBERT, Guita Grin; GREGORI, Maria Filomena. Violência e gênero: novas propostas, velhos dilemas. Revista Brasileira de Ciências Sociais, v. 23, n. 66, p. 165-185, fev. 2008.

GREGORI, Maria Filomena. Cenas e queixas: um estudo sobre mulheres, relações violentas e a prática feminista. São Paulo: Paz e Terra, 1993.

HARAWAY, Donna. Staying with the trouble: Making Kin in the Chthulucene. Durham: Duke University Press, 2016.

HARAWAY, Donna. When species meet. Minneapolis: University of Minnesota Press, 2008.

LATHER, Pathi. Methodology as subversive repetition: practices toward a feminist double science. Paper apresentado na Annual Meeting of the American Educational Research Association, New York City, NY, EUA, 1996. (mimeo).

LATOUR, Bruno. War of the worlds: What about Peace?. Chicago: Prickly Paradigm Press, 2002.

LARROSA, Jorge. Tecnologias do eu e educação. In: SILVA, Tomaz Tadeu (Org.). O sujeito da educação: estudos foucaultianos. Petrópolis: Vozes, 1994, p.35-86.

MACEDO, Elizabeth. As demandas conservadoras do Movimento Escola sem Partido e a Base Nacional Curricular Comum. Educação e Sociedade, Campinas, v. 38, n. 139, p.507-524, abr./jun., 2017a

. Mas e a escola não tem que ensinar? Conhecimento, reconhecimento e alteridade na teoria do currículo. Currículo sem Fronteiras, v. 17, n. 3, p. 539-554, set./dez. 2017 b.

PARAISO, Marlucy Alves. A ciranda do currículo com gênero, poder e resistência. Currículo Sem Fronteiras, v. 16, p. 388-415, 2016a.

Currículo e relações de gênero: entre o que se ensina e o que se pode aprender. Linhas, Florianópolis, v. 17, n. 33, p. 206-237, jan./abr. 2016b.

RANNIERY, Thiago. Vem cá, e se fosse ficção? Práxis Educativa, Ponta Grossa, v. 13, n. 3, p. $982-$ 1002, set./dez. 2018 
Sociedad, v. 25, p. 19-49, 2017a.

. "Sexualidade na escola": é possível é ir além da máquina de diferentes?. In: MACEDO, Elizabeth; RANNIERY, Thiago. (org.). Currículo, sexualidade e ação docente. Petropólis: DP et Alii, 2017b. p. 213-238.

. Currículo, normatividade e políticas de reconhecimento a partir de trajetórias escolares de 'meninos gays'. Education Policy Analysis Archives, v. 25, p. 1-32, 2017c.

RANNIERY, Thiago; LEMOS, Paula. Gênero pode ser uma categoria útil para o ensino de biologia?. In: VILELA, Mariana et al (orgs). Aqui tem Currículo! Saberes em diálogo no ensino de biologia. Curitiba: Prismas, 2018. (no prelo).

REIS, Cristina D'Ávila; PARAÍSO, Marlucy Alves. Normas de gênero em um currículo escolar: a constituição dicotômica de corpos e posições de sujeito meninos-alunos. Estudos Feministas, v. 22, n. 1, p. 237-255, 2014.

SARTI, Cynthia. A vítima como figura contemporânea. Caderno CRH, Salvador, v. 24, n.61, p. 51-61, jan./abr. 2011.

SPIVAK, Gaytrick. Outside in the teaching machine. New York : Routledge, 1993.

STENGERS, Isabelle. A proposição cosmopolítica. Revista do Instituto de Estudos Brasileiros, Brasil, n. 69, p. 442-464, abr. 2018.

ST. PIERRE, Elizabeth. Poststructural feminism in education: an overview. International Journal of Qualitative Studies In Education, v. 13, n. 5, p. 477-515.

WHITMAN, Walt. Eu canto o corpo elétrico. Disponível em: https://gavetadoivo.wordpress.com/2011/07/12/um-poema-de-walt-whitman-traduzido-por-ivobarroso/. Acesso em: outubro de 2018.

WITTIG, Monique. O Pensamento Hétero. Ensaio, 1980. Acesso em: <http://mulheresrebeldes.blogspot.com.br/2010/07/sempre-viva-wittig.html> 